\title{
Clinical and genetic studies of Birt-Hogg-Dubé syndrome
}

\author{
S K Khoo, S Giraud, K Kahnoski, J Chen, O Motorna, R Nickolov, O Binet, D Lambert, \\ J Friedel, R Lévy, S Ferlicot, P Wolkenstein, P Hammel, U Bergerheim, M-A Hedblad, \\ M Bradley, B T Teh, M Nordenskiöld, S Richard
}

See end of article for authors' affiliations Correspondence to: Génétique Oncologique

EPHE, Faculté de Médecine Paris-Sud, 94276 Le

Kremlin Bicêtre, France; stephane.richard@

kb.u-psud.fr

Revised version received 3 October 2002

Accepted for publication

3 October 2002
Birt-Hogg-Dubé syndrome (BHD) is an autosomal dominant cancer syndrome characterised by benign skin tumours, renal tumours, and spontaneous pneumothorax. The gene has been mapped to chromosome 17p11.2 and recently identified, expressing a novel protein called folliculin. We report the clini$\mathrm{cal}$ and genetic studies of four sporadic BHD cases and four families with a total of 23 affected subjects. Haplotype analysis of these families using BHD linked markers showed they did not share the same affected alleles, excluding common ancestry. Mutation analysis of the BHD gene identified two germline mutations on exon 11 (c.1733ins C and c. 1733delC) in three of four families as well as two of four sporadic cases. A novel somatic mutation, c. 1732delTCinsAC, was detected in a BHD related chromophobe renal carcinoma. Our results confirmed the $\left(\mathrm{C}_{8}\right.$ tract in exon 11 as a mutational hot spot in $B H D$ and should always be considered for future genetic testing. Our observation also indicated that the second hit (of Knudson's two hit theory) in some BHD related tumours is in the form of somatic mutation rather than $\mathrm{LOH}$. In a large French family in which eight affected subjects carry the c. 1733delC mutation, a phenocopy who has multiple episodes of spontaneous pneumothorax was identified. A total of five mutation carriers (aged between 37 to 66) did not have any evidence of BHD features, suggesting either reduced penetrance or late age of onset of the disease. In addition, six out of eight affected subjects who have positive germline mutation have confirmed neoplastic colonic polyps, indicating that colorectal neoplasia is an associated feature of BHD in some families. Our studies have observed several interesting genetic features in BHD: (1) the poly $(C)$ tract in exon 11 as a mutational hot spot; (2) the existence of phenocopy; (3) reduced penetrance or late age of onset of disease; (4) association with colorectal neoplasia in some families; and (5) somatic mutation instead of $\mathrm{LOH}$ as the second hit in BHD tumours.
B irt-Hogg-Dubé syndrome (BHD, OMIM 135150) is an autosomal dominant disease characterised by the cutaneous triad of multiple fibrofolliculomas, trichodiscomas, and acrochordons, which was first described in 1977. ${ }^{1}$ Clinically, it exhibits numerous, asymptomatic, skin coloured, dome-shaped papules over the face, neck, and upper trunk. Fibrofolliculomas and trichodiscomas are both benign tumours of the pilar apparatus. Fibrofolliculomas arise from both mesodermal and ectodermal components, whereas trichodiscomas represent fibrovascular proliferations of the hair disc. ${ }^{2}$ It is difficult to distinguish fibrofolliculomas and trichodiscomas clinically, and histologically they both consist of follicular hamartomas. BHD patients sometimes lack acrochordons, ${ }^{3}{ }^{4}$ which were later defined as histological variations of the trichodiscoma/fibrofolliculoma. ${ }^{5}$ Cutaneous lesions in BHD usually appear in the third or fourth decades of life and persist indefinitely.

A wide spectrum of features has also been described in BHD along with the triad of dermatological lesions. ${ }^{6}$ These include diverse classes of renal tumours such as oncocytoma, chromophobe, papillary, and clear cell renal carcinomas (RCCs). ${ }^{7-9}$ Spontaneous pneumothorax and/or pulmonary cysts associated with BHD have also been frequently reported. ${ }^{8}{ }^{10}$ In addition, colonic neoplasia was also described in earlier reports. ${ }^{6}{ }^{10-12}$ However, not a single case of colonic neoplasia was found in a recent study reviewing the clinical features of 152 BHD patients from 49 families. ${ }^{8}$ The same group of researchers also concluded that there is no significant risk increment for the development of colon polyps or colon carcinomas in subjects with BHD. ${ }^{13}$

The BHD gene was mapped to chromosome 17pll.2 based on genome wide linkage studies. ${ }^{914}$ The BHD gene was recently identified and expresses a novel protein called folliculin but its function remains unknown. ${ }^{15}$ The identification of this gene provides an opportunity for genetic testing which will lead to a better understanding of the disease. In this study, we report clinical and genetic studies of four apparently sporadic cases and four families with 23 affected subjects from France and Sweden.

\section{MATERIAL AND METHODS}

Subjects

One three generation BHD kindred with 10 affected subjects (F518) (fig l), one two generation kindred with five affected subjects (F598), one four generation kindred with 10 affected subjects (S001), and one nuclear kindred with two affected subjects (S002) were studied, along with four sporadic cases (S003, S006, F641, F676). All samples were from either France or Sweden. All studies were approved by the Ethical Committee at Le Kremlin-Bicêtre University Hospital in France, the Karolinska Hospital Ethics Committee in Sweden, and the Internal Review Board of the Van Andel Research Institute in the USA. Informed consent was obtained from all participating patients and family members.

Blood samples were obtained and DNA was extracted from lymphocytes using the Qiagen Maxi kit (Qiagen, California, USA). A chromophobe renal carcinoma from an affected member in family S001 was also included for DNA extraction.

\section{Clinical studies}

Evaluation was carried out at several hospitals in France as well as at the Department of Dermatology and Venereology, and the Department of Clinical Genetics in Karolinska Hospital. Each patient underwent thorough skin examination and diagnosis was confirmed histologically by biopsy. Abdominal 

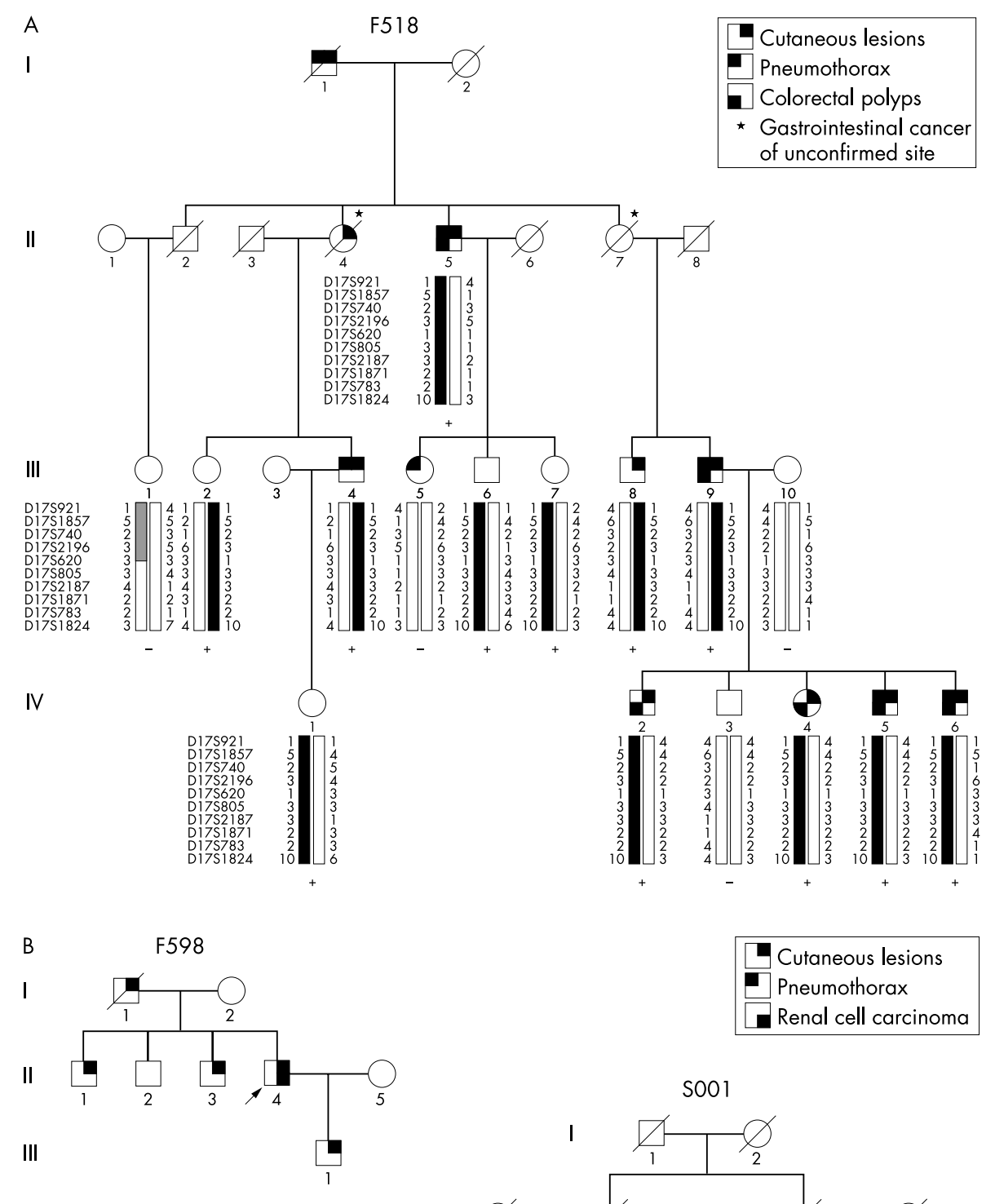

II
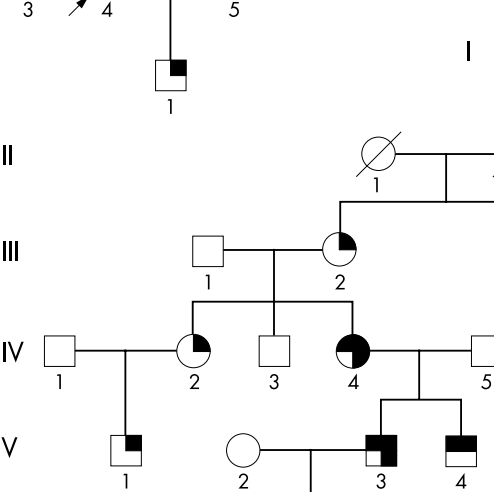

S001

IV

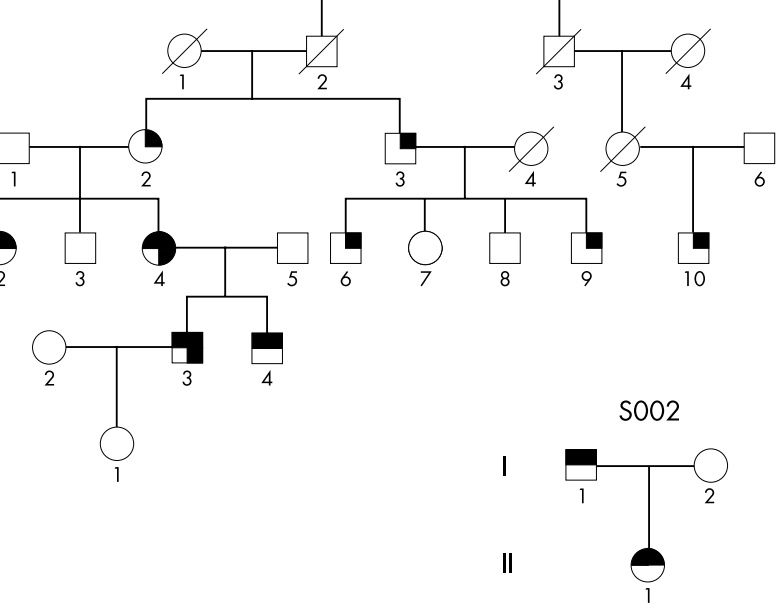

Figure 1 (A) Pedigree and haplotype of family F5 18 with BHD. Blackened bars represent the affected haplotype. + designates subjects with the c. 1733delC mutation detected and - subjects without mutation. Note the four clinically unaffected subjects (III.2, III.6, III.7, and IV.1) who are BHD haplotype and mutation carriers. III.5 is a phenocopy. Part of the affected haplotype shown in the striped bar (III. 1) with the absence of mutation suggests the coincidence of possible allele sharing originating from an unaffected parent (II. 1 or II.2). (B) Families F598, S001, and SOO2 with BHD.

CT scans and/or renal ultrasonography were applied to detect the presence of renal tumours. Thoracic CT scans were performed to scan for abnormalities of the lungs and colonoscopy was used to detect colorectal neoplasia.
Genotyping, haplotyping, and loss of heterozygosity (LOH) analysis

Ten microsatellite markers from chromosome 17p12-q11.2, D17S921, D17S1857, D17S740, D17S2196, D17S620, D17S805, 
Table 1 Clinical features of 32 subjects from three familial and four sporadic BHD cases

\begin{tabular}{|c|c|c|c|c|c|c|c|c|}
\hline Family & Subject & $\begin{array}{l}\text { Current } \\
\text { age }\end{array}$ & $\begin{array}{l}\text { Cutan- } \\
\text { eous } \\
\text { lesions }\end{array}$ & Renal lesions & Colorectal lesions & $\begin{array}{l}\text { Pneumo- } \\
\text { thorax }\end{array}$ & Other lesions & Mutation \\
\hline \multirow[t]{20}{*}{ F518 } & I. 1 & 74 & $\mathrm{x}$ & NA & NA & Multiple & & NA \\
\hline & 1.2 & 78 & None & NA & NA & None & & NA \\
\hline & II.2 & 69 & None & None & None & None & $\begin{array}{l}\text { Liver cancer (alcoholic cirrhosis), } \\
\text { pleurisy }\end{array}$ & NA \\
\hline & 11.4 & 54 & $x x$ & NA & NA & None & $\begin{array}{l}\text { Gastrointestinal cancer (site } \\
\text { uncertain) }\end{array}$ & NA \\
\hline & 11.5 & 77 & $x x$ & None & $\begin{array}{l}8 \text { colorectal polyps } \\
\text { (tubulovillous/tubular) }\end{array}$ & Three & & c. $1733 \mathrm{delC}$ \\
\hline & 11.7 & 75 & None & None & NA & None & $\begin{array}{l}\text { Gastrointestinal cancer (site } \\
\text { uncertain) }\end{array}$ & NA \\
\hline & III. 1 & 45 & None & None & None & None & & None \\
\hline & III. 2 & 66 & None & NA & NA & None & & c. $1733 \mathrm{del} C$ \\
\hline & III. 4 & 64 & $x x$ & None & None & Multiple & Pleurisy & c. 1733 delC \\
\hline & III. 5 & 47 & None & None & NA & Multiple & & None \\
\hline & III.6 & 53 & None & NA & NA & None & & c. $1733 \mathrm{del} C$ \\
\hline & III.7 & 40 & None & NA & NA & None & & c. 1733 delC \\
\hline & III. 8 & 68 & $x x$ & NA & None & None & & c. 1733 delC \\
\hline & III.9 & 71 & $x x x$ & 2 renal cysts & Colorectal polyps (histology NA) & Multiple & & c. $1733 \mathrm{delC}$ \\
\hline & IV.1 & 37 & None & None & NA & None & & c. $1733 \mathrm{del} C$ \\
\hline & IV.2 & 45 & $\mathrm{x}$ & NA & 1 colon polyp (tubular) & None & Sigmoid diverticulosis & c. 1733 delC \\
\hline & IV.3 & 46 & None & NA & NA & None & & None \\
\hline & IV.4 & 41 & $x x$ & None & $\begin{array}{l}4 \text { colorectal polyps } \\
\text { (villous/tubular) }\end{array}$ & None & & c. $1733 \mathrm{del} C$ \\
\hline & IV.5 & 37 & $x$ & None & 1 colon polyp (tubulovillous) & Multiple & & c. 1733 delC \\
\hline & IV.6 & 47 & $x x$ & None & Colorectal polyps (tubular) & Multiple & Tonsil squamous cell cancer & c. $1733 \mathrm{delC}$ \\
\hline \multirow[t]{6}{*}{ F598 } & I. 1 & $?$ & $x$ & NA & NA & None & Lung carcinoma & NA \\
\hline & II. 1 & 65 & $x x$ & None & NA & None & Nodular cutaneous elastoidosis & c. 1733 delC \\
\hline & 11.2 & 41 & None & NA & NA & None & & c. 1733 delC \\
\hline & 11.3 & 52 & $x x x$ & None & NA & None & $\begin{array}{l}\text { Leg superficial spreading } \\
\text { malignant melanoma }\end{array}$ & c. $1733 \mathrm{delC}$ \\
\hline & 11.4 & 65 & $x x x$ & Clear cell RCC & NA & One & Cutaneous and parotid metastases & c. 1733 delC \\
\hline & III. 1 & 37 & $x x x$ & None & NA & None & Retrobulbar neuropathy & c. $1733 \mathrm{delC}$ \\
\hline \multirow[t]{2}{*}{ SOO2 } & I. 1 & 66 & $x x x$ & None & NA & Multiple & & c. 1733ins $C$ \\
\hline & II. 1 & 39 & $x$ & None & NA & Three & & c. 1733insC \\
\hline \multicolumn{9}{|c|}{ Sporadic cases } \\
\hline & S003 & 49 & $x x$ & None & NA & None & & c. 1733insC \\
\hline & S006 & 61 & $x x$ & None & Colon polyps (histology NA) & One & Sarcoma breast & None \\
\hline & F641 & 60 & $x x$ & $\begin{array}{l}\text { Unclassified } \\
\text { RCC }\end{array}$ & NA & None & Lung metastasis & c. $1733 \mathrm{delC}$ \\
\hline & F676 & 63 & $x x x$ & None & NA & None & $\begin{array}{l}\text { Meningioma; vulvar epitheliomas; } \\
\text { finger histiocytofibroma; } \\
\text { Hashimoto thyroiditis }\end{array}$ & None \\
\hline
\end{tabular}

D17S2187, D17S1871, D17S783, and D17S1824, were genotyped on all lymphocytes and tumour DNA. PCR was performed in a $7.5 \mu \mathrm{l}$ reaction volume containing $0.17 \mu \mathrm{mol} / \mathrm{l}$ each of fluorescence labelled forward and unlabelled reverse primer, $10 \mathrm{mmol} / \mathrm{l}$ Tris- $\mathrm{HCl}$ ( $\mathrm{pH} \mathrm{8.3),} 50 \mathrm{mmol} / \mathrm{l} \mathrm{KCl}, 4 \mathrm{mmol} / \mathrm{l}$ $\mathrm{MgCl}_{2}, 0.3 \mathrm{U}$ AmpliTaq Gold polymerase (ABI), $0.25 \mathrm{mmol} / \mathrm{l}$ dNTPs (Invitrogen), and 15 ng of genomic DNA. PCR was performed using PE 9700 thermocyclers with an initial 10 cycles ( 15 seconds at $94^{\circ} \mathrm{C}, 15$ seconds at $55^{\circ} \mathrm{C}, 30$ seconds at $72^{\circ} \mathrm{C}$ ) followed by 20 cycles ( 15 seconds at $89^{\circ} \mathrm{C}, 15$ seconds at $55^{\circ} \mathrm{C}$, 30 seconds at $72^{\circ} \mathrm{C}$ ). PCR amplified products were then denatured and run on an ABI 377 genetic analyser (Applied Biosystem). Allele sizes were assigned using Genescan v 3.1 and Genotyper v 2.5 software (Applied Biosystem). Pedigrees were drawn using Cyrillic V 2.1 and haplotypes were confirmed with Genehunter v 2.1. ${ }^{16} \mathrm{LOH}$ was performed by comparing the genotypes of tumour DNA with matched lymphocyte DNA. LOH was determined as previously described. ${ }^{17}$

\section{Mutation analysis}

For mutation analysis of $B H D$, we used the primer sequences and PCR conditions reported by Nickerson et al ${ }^{15}$ to amplify all 14 exons. Amplicons were verified by gel electrophoresis before purification with Multiscreen PCR cleanup plates (Mil- lipore). Sequencing reactions were performed using Big Dye Terminator (Applied Biosystem), purified through Sephadex G-50 (Pharmacia), and run on an ABI 3700 genetic analyser. We aligned and analysed all sequences by Blast 2 Sequences ${ }^{18}$ as well as manually.

\section{RESULTS}

\section{Clinical data}

The clinical data of all affected subjects, except those from family S001, ${ }^{9}$ are summarised in table 1. Family F518 (fig 1A) is a large three generation family first described by Binet et $a l^{11}$ in 1986. This family has 10 members with typical cutaneous fibrofolliculomas and was therefore considered as affected with BHD. Multiple recurrent pneumothorax occurred in six of the affected members. III.5 (aged 47) who has many recurrent pneumothorax was initially considered as affected, but was tested negative for the mutation, therefore representing a phenocopy. Regarding the occurrence of kidney tumours, apart from two benign cysts detected in III.9 (aged 71), none of the eight examined affected patients has a renal tumour. In contrast, neoplastic colorectal polyps of different histological types (villous, tubulovillous, or tubular), mainly with a mild to moderate degree of dysplasia, were observed in six of the affected patients: II.5, III.9, IV.2, IV.4, IV.5 and IV.6. II.7 died at 

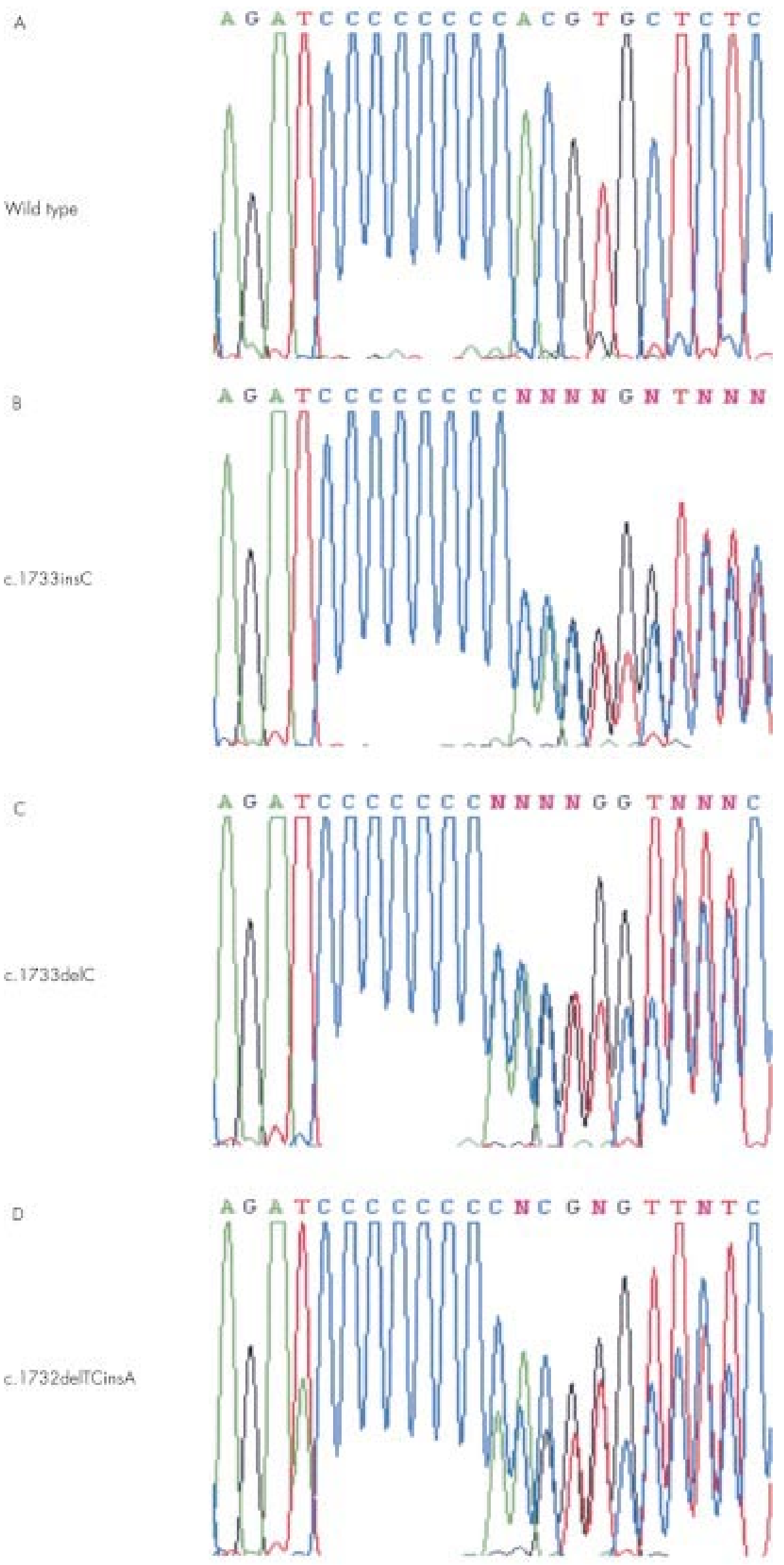

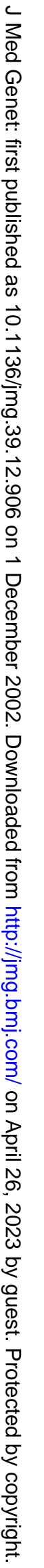

Figure 2 Representative $B H D$ sequence of normal $(A)$ and affected subjects $(B, C)$, as well as a novel c. 1732delTCinsA mutation (D) detected in a chromophobe tumour. These results support the poly $C$ tract as a mutational hot spot in exon 11. 
the age of 75 years without detection of cutaneous lesions. She and her dead sister (II.4) were both obligate gene carriers (fig 1A), and the cause of death in both cases was thought to be gastrointestinal cancer of probably colonic origin, although no pathological data could be retrieved to ascertain the sites of cancer. In addition to BHD and BHD related symptoms, tonsil squamous cell cancer was found in affected member IV.6 as well as the gastrointestinal cancer mentioned above in both obligate carriers (II.4 and II.7).

Family F598 (fig 1B) is a newly described two generation BHD family from France. Five members are affected with typical fibrofolliculomas and therefore considered to be affected with BHD. The proband (II.4) has a history of right nephrectomy at the age of 20 because of clear cell renal carcinoma, then removal of isolated bilateral parotid metastases 43 years later. The other three affected subjects showed normal renal ultrasonography. None of the patients experienced pneumothorax and we did not perform colonoscopy on the patients in this family. Other cancers detected in this family are superficial spreading malignant melanoma in the leg (II.3) and lung carcinoma in a dead obligate carrier (I.1).

Family S001 (fig 1B) has been previously described ${ }^{9}$ and has 10 members affected with BHD. One subject (V.4) had a spontaneous pneumothorax and atypical cyst in his kidney, while two other members (IV.4 and V.3) have renal cell carcinoma as well as pneumothorax. Other clinical features included sarcoma dorsi, fibroadenomatosis of the breast, and multiple lipomas.

Family S002 (fig 1B) is a newly ascertained BHD Swedish family. Multiple skin lesions were detected in the father (I.1) and daughter (II.1). Both have pneumothorax but no kidney lesion. Colonoscopy was not performed.

S003 and S006 are sporadic cases of BHD. In both cases, both of their parents have died and their sibs did not show any sign of cutaneous lesions or other BHD related features. Fibrofolliculomas were found in both patients, but renal ultrasound did not show any abnormalities. One episode of pneumothorax, unclassified colon polyps, and breast sarcoma were detected in subject S006.

Sporadic case F641 is a white male with multiple face and neck fibrofolliculomas. His father has died and he has lost contact with his mother. At the age of 35, he had a right nephrectomy where an $8 \mathrm{~cm}$ "malignant oncocytoma" infiltrating the capsule and locoregional nodes was dissected. He was then treated with BCG vaccine immunotherapy. In 1999, a thoracic CT scan of this patient showed a $3 \mathrm{~cm}$ metastasis of the upper right lobe of the lung and many bilateral emphysematous blebs. Resection of a segment of the lung showed renal tumour metastasis with papillary structures and many infrapleural emphysematous blebs. Reinterpretation of histological slides of the initial tumour gave the diagnosis of an unclassifiable malignant Fuhrman grade 4 renal cell tumour with a preponderant eosinophilic contingent. Colonoscopy was not performed in this patient.

Case F676 is a white female whose parents did not have BHD syndrome. Both her parents have died. She was diagnosed with BHD at age 51, owing to the presence of multiple fibrofolliculomas on her face and hands. This patient has neither renal tumour nor pneumothorax. Colonoscopy performed at the age of 61 showed absence of lesions.

\section{Mutations}

Three familial cases (F5 18, F598, S002) and two sporadic cases (S003, F641) showed mutations, all in exon 11. A c.1733insC (fig 2B) germline mutation was detected in $\mathrm{S} 002$ and S003, while all affected subjects from a family with colonic neoplasia (F518) have a c.1733delC (fig 2C) germline mutation, along with F598 and F641. The $\mathrm{C}$ deletion mutation in F518 also cosegregated with four BHD haplotype carriers (III.2, III.6, III.7, and IV.1, fig IA). The same pattern of cosegregation
Table 2 Disease haplotype of four familial BHD cases showed that they did not share the same affected alleles. Matching mutation analysis results are also included. BHD is located between D17S740 and D17S2 196. Bold numbers represent the affected haplotype

\begin{tabular}{lllll}
\hline \multirow{5}{*}{ Markers } & \multicolumn{4}{l}{ Family } \\
\cline { 2 - 5 } & S001 & S002 & 518 & 598 \\
\hline D17S1857 & $\mathbf{3 / 4}$ & $\mathbf{7 / 1}$ & $4 / 6$ & $\mathbf{3} / 4$ \\
D17S740 & $\mathbf{2} 2$ & $2 / 5$ & $2 / 1$ & $3 / 3$ \\
D17S2196 & $6 / 5$ & $3 / 1$ & $3 / 6$ & $2 / 5$ \\
D17S620 & $1 / 1$ & $3 / 3$ & $3 / 1$ & $1 / 1$ \\
Mutation & None & 1733 insC & 1733 delC & 1733 delC \\
\hline
\end{tabular}

was also observed in one BHD haplotype carrier (II.2) in family F598. A novel mutation, c.1733delTCinsA (fig 2D), in exon 11 not reported before was detected in the chromophobe tumour from an affected subject (V.3) from family S001, where no germline mutation was present in any affected members. Two isolated cases (S006 and F676) also did not show any germline mutation.

\section{Haplotypes and LOH}

All genotype and haplotype results confirmed the BHD region that was previously mapped. ${ }^{9}{ }^{14}$ A detailed haplotype for family F518 is shown in fig 1A. In this family, four unaffected subjects (III.2, III.6, III.7, and IV.1) shared the same haplotype as the rest of the affected subjects and are defined as BHD haplotype carriers. The four families did not share the same affected haplotype (table 2). In family S001, no LOH was found in the chromophobe renal carcinoma of an affected member who has the disease haplotype (V.3) (data not shown).

\section{DISCUSSION}

BHD is a classical hereditary cancer syndrome. The identification of the BHD gene facilitates the genetic characterisation of the patients and their tumours, including genotypephenotype correlation, as well as functional studies of the gene. In the present study, three different frameshift mutations in exon 11, c.1733insC, c.1733delC, and c.1732delTCinsAC, were identified. The c.1733insC and c.1733delC mutations were germline mutations detected in $75 \%(3 / 4)$ of familial cases and 50\% (2/4) of sporadic cases. Unfortunately DNA from the parents of the sporadic patients was unavailable for further analysis to determine if they were de novo mutations. The c.1732delTCinsAC mutation is a novel somatic mutation that was detected in a chromophobe renal carcinoma of a BHD patient. All mutations involve a poly $\mathrm{C}$ tract (nt 1733-1740) in exon 11, confirming the hypermutable $(C)_{8}$ tract recently reported, where 18 c.1733insC mutations and nine c.1733delC mutations were identified in 62 BHD patient samples. ${ }^{15}$ This instability appears to be "slippage" during DNA replication, resulting in gains or losses of repeat units, $^{21}$ such as in BRCA1, NF1, and APC, causing cancer predisposition..$^{22} 24$ To date, besides exon 11, three other exons $(7,9,12)$ were found to harbour BHD mutations. ${ }^{15}$ All four exons should be the focus of genetic testing, leading to saving in cost, labour, and time.

Haplotype analysis of four BHD families (table 2) showed a different disease haplotype within each family, implying that they are unlikely to share a common ancestor and ruling out the possibility of a founder effect in their mutations. All affected members in family S001 shared the same disease haplotype, which was mapped on chromosome 17pl1.2, ${ }^{9}$ but none of them have germline mutation. This can be explained 
by (1) mutation in the promoter region; (2) a small germline deletion between marker D17S740 and D17S2196; or (3) a second BHD gene located in the vicinity of the mapped locus. The difference between family S001, which has no germline mutation, and those cases which have mutations (F518, F598, S002, S003, and F641) is the presence of breast tumours in some BHD members in S001. Interestingly, breast tumour also occurred in S006, who is a sporadic case without any germline mutation.

The majority of hereditary cancer syndrome genes follow the paradigm of a tumour suppressor gene or Knudson's two hit theory. ${ }^{19}$ Tumours usually carry a copy of an inactivating germline mutation and lose the other copy via loss of heterozygosity ( $\mathrm{LOH})$, methylation, or somatic mutation. $\mathrm{LOH}$ is most commonly found in hereditary tumours, but in BHD only $17 \%$ of hereditary renal tumours showed $\mathrm{LOH}^{20}$ In the only BHD related chromophobe tumour available in this study, $\mathrm{LOH}$ could not be detected; instead a somatic inactivating mutation, which is absent in the matched constitutional DNA, was identified. The somatic mutation represents the second hit of Knudson's theory, and should be screened for in BHD related tumours without $\mathrm{LOH}$. Other mechanisms, such as hypermethylation, may also be involved and merit further investigation.

Several groups have reported cases of colorectal neoplasia in BHD families, ${ }^{60-12}$ but a more recent clinical study ${ }^{8}$ showed the absence of colorectal neoplasia in 152 patients from 49 families. One study ${ }^{13}$ showed statistical non-significance comparing the presence of colon cancer in $111 \mathrm{BHD}$ affected and 112 BHD unaffected subjects, as well as colon polyps of 45 BHD affected and 38 BHD unaffected subjects, concluding that there is no risk increment for the development of colon polyps or colon carcinoma in BHD patients. In the present study, we identified six family members with true neoplastic colonic polyps and two with probable colon cancer, indicating that colorectal neoplasia is involved in this particular BHD family. It is not uncommon to find certain unique clinical features associated with certain families in hereditary cancer syndromes. Environmental or additional genetic factors may be the possible cause. The latter would suggest the involvement of a "modifying" gene(s) which is related to BHD, or a distinct colorectal neoplasia related gene which happened to cosegregate with the BHD gene in some of the family members. Additional studies will be necessary fully to understand the role of BHD in colorectal tumorigenesis. In addition, our present study indicates that BHD patients may have a predisposition to other malignancies, such as melanoma, as well as gastrointestinal, lung, head and neck, and breast cancers.

Subject III.5 from family F518 had multiple episodes of spontaneous pneumothorax but without any skin lesions. The absence of germline mutation suggests that she is a phenocopy. However, c.1733delC germline mutations were detected in her two brothers, III.6 and III.7 (aged 53 and 40, respectively), although they have not yet developed any symptoms of BHD. In addition, two other subjects from F518 (III.2 and IV.1, aged 66 and 37 respectively) and another from F598 (II.2, aged 41) were also found to have germline mutations but have no clinical evidence of the disease. The findings can be explained by the late age of onset of BHD syndrome, although it is also quite possible that BHD has reduced penetrance in certain people. Further and long term studies on these families are warranted to address these issues. This study also shows the importance of mutation analysis in at risk subjects. Long term follow up and genetic counselling should be provided to gene carriers.

In summary, we have described the clinical and genetic findings in 23 affected cases from four BHD families and four sporadic cases. We confirmed a hot spot for BHD mutation, the presence of phenocopies, late age of onset or reduced penetrance of $\mathrm{BHD}$, association with colorectal neoplasia, and the nature of the second hit in a BHD related tumour.

\section{ACKNOWLEDGEMENTS}

The first two authors contributed equally to this work. We would like to thank all the BHD patients and family members who participated in the studies. We also thank Dr J Amiel, Dr E Beltzer-Garelly, Dr H J Bertrand, Dr C Bizollon, Professor G Benoît, Dr J M Corréas, Dr B David, Dr W Godard, Professor J P Grünfeld, Dr J P Jacquot, Professor A Jardin, Dr G Turcat, and Dr G Allègre for their very valuable help. This study was supported by grants from the French Ligue Nationale Contre le Cancer (Comité du Cher), the Swedish Cancer Society, and the Van Andel Foundation.

\section{Authors' affiliations}

S K Khoo, K Kahnoski, J Chen, O Motorna, B T Teh, Laboratory of Cancer Genetics, Van Andel Research Institute, Grand Rapids, MI 49503, USA

S Giraud, S Richard, Génétique Oncologique EPHE, UPRESS 1602, and Service d'Urologie, CHU Bicêtre, 94276 Le Kremlin Bicêtre, France S Giraud, Laboratoire de Génétique, Hôpital E Herriot, 69437 Lyon Cedex, France

R Nickolov, Department of Mathematical Sciences, Michigan

Technological University, Houghton, MI 49931, USA

O Binet, Service de Dermatologie, Fondation Rothschild, 75018 Paris, France

D Lambert, Service de Dermatologie, CHU, 21000 Dijon, France

J Friedel, Service de Dermatologie, Centre Hospitalier, 71100 Chalons sur Saône, France

R Lévy, Service d'Oncologie, Clinique de l'Orangerie, 94170 Le Perreux sur Marne, France

S Ferlicot, Laboratoire d'Anatomie Pathologique, CHU Bicêtre, 94276 Le Kremlin Bicêtre, France

P Wolkenstein, Service de Dermatologie, CHU Henri Mondor, 94000 Créteil, France

P Hammel, Service de Gastroentérologie, Hôpital Beaujon, 92000 Clichy, France

U Bergerheim, Department of Urology, Danderyds Hospital, Danderyd, Sweden

M-A Hedblad, M Bradley, Department of Dermatology and Venereology, Karolinska Hospital, Karolinska Institutet, Stockholm, Sweden

M Bradley, Program in Epithelial Biology, Stanford University School of Medicine, Stanford, CA 94305, USA

M Nordenskjöld, Departments of Molecular Medicine and Clinical

Genetics, Karolinska Hospital, Karolinska Institutet, Stockholm,

S Richard, Service de Néphrologie, Hôpital Necker, Paris, France

\section{REFERENCES}

1 Birt AR, Hogg GR, Dubé WJ. Hereditary multiple fibrofolliculomas with trichodiscomas and acrochordons. Arch Dermatol 1977:113:1674-7.

2 Weintraub R, Pinkus H. Multiple fibrofolliculomas (Birt-Hogg-Dubé) associated with a large connective tissue nevus. J Cutan Pathol 1977;4:289-99.

3 Foucar K, Rosen T, Foucar E, Cochran RJ. Fibrofolliculoma: a clinicopathologic study. Cutis 1981;28:429-32.

4 Moreno A, Puig L, de Moragas JM. Multiple fibrofolliculomas and trichodiscomas. Dermatologica 1985; 171:338-42.

5 De la Torre C, Ocampo C, Doval IG, Losada A, Cruces M. Acrochordons are not a component of the Birt-Hogg-Dubé syndrome does this syndrome exist? Case reports and review of the literature. Am J Dermatol 1999;21:369-74.

6 Schulz T, Hartschuh W. Birt-Hogg-Dubé syndrome and Hornstein-Knickenberg-syndrome are the same. Different sectioning techniques as the cause of different histology. J Cutan Pathol 1999;26:55-61.

7 Roth JS, Rabinowitz AD, Benson M, Grossman ME. Bilateral renal cell carcinoma in the Birt-Hogg-Dubé syndrome. J Am Acad Dermatol 1993;29:1055-6

8 Toro J, Glenn G, Duray P, Darling T, Weirich G, Zbar B, Linehan M, Turner M. Birt-Hogg-Dubé syndrome: a novel marker of kidney neoplasia. Arch Dermatol 1999;135:1195-202

9 Khoo SK, Bradley M, Wong FK, Hedblad MA, Nordenskjöld M, Teh BT. Birt-Hogg-Dubé syndrome: mapping of a novel hereditary neoplasia gene to chromosome 17p12-q11.2. Oncogene 2001;20:5239-42.

10 Chung JY, Ramos-Caro FA, Beers B, Ford M, Flowers F. Multiple lipomas, angiolipomas and parathyroid adenomas in a patient with Birt-Hogg-Dubé syndrome. Int J Dermatol 1996;35:365-7.

11 Binet O, Robin J, Vicart M, Ventura G, Beltzer-Garelly E. Fibromes périfolliculaires, polypose colique familiale, pneumothorax spontanés familiaux. Ann Dermatol Venereol 1986:113:928-30.

12 Rongioletti F, Hazini R, Gianotti G, Rebora A. Fibrofolliculomas, tricodiscomas and acrochordons (Birt-Hogg-Dubé) associated with intestinal polyposis. Clin Exp Dermatol 1989;14:72-4.

13 Zbar B, Alvord WG, Glenn G, Turner M, Pavlovich CP, Schmidt L, Walther M, Choyke P, Weirich G, Hewitt SM, Duray P, Gabril F, Greenberg C, Merino M, Toro J, Linehan WM. Risk of renal and colonic 
neoplasms and spontaneous pneumothorax in the Birt-Hogg-Dubé syndrome. Cancer Epidemiol Biomarkers Prev 2002;11:393-400.

14 Schmidt LS, Warren MB, Nickerson ML, Weirich G, Matrosova V, Toro JR, Turner ML, Duray P, Merino M, Hewitt S, Pavlovich CP, Glenn G, Greenberg CR, Linehan WM, Zbar B. Birt-Hogg-Dubé syndrome, a genodermatosis associated with spontaneous pneumothorax and kidney neoplasia, maps to chromosome 17p1 1.2. Am J Hum Genet 2001;69:876-82

15 Nickerson ML, Warren MB, Toro JR, Matrosova V, Glenn G, Turner ML, Duray $P$, Merino M, Choyke P, Pavlovich CP, Sharma N, Walther M, Munroe D, Hill R, Maher E, Greenberg C, Lerman MI, Linehan WM, Zbar B, Schmidt LS. Mutations in a novel gene lead to kidney tumors, lung wall defects, and benign tumors of the hair follicle in patients with the Birt-Hogg-Dubé syndrome. Cancer Cell 2002;2:157-64

16 Kruglyak L, Daly M, Reeve-Daly MP, Lander ES. Parametric and nonparametric linkage analysis: a unified multipoint approach. Am J Hum Genet 1996;58:1347-63.

17 Giraud S, Choplin H, Teh BT, Lespinasse J, Lenoir G, Hamon P, Calender A. A large MEN1 family with clinical expression suggestive of anticipation. J Clin Endocrinol Metab 1997;82:3487-92.

18 Tatusova TA, Madden TL. Blast 2 sequences - a new tool for comparing protein and nucleotide sequences. FEMS Microbiol Lett 1999; 174:247-50
19 Teh BT, Larsson C, Nordenskjöld M. Tumor suppressor genes. Anticancer Res 1999;19:4715-28

20 Pavlovich CP, Schmidt LS, Warren MB, Weirich G, Afonso A, Phillips JL, Ried T, Linehan M, Zbar B. Genetic analysis of renal cell carcinomas in Birt-Hogg-Dubé syndrome. In: Proceedings of the 93rd annual meeting of American Association for Cancer Research. AACR, San Francisco, California, 2002:632

21 Minnick DT, Kunkel TA. DNA synthesis errors, mutators and cancer. Cancer Surv 1996;28:3-20.

22 Rodenhiser D, Chakraborty P, Andrews J, Ainsworth P, Mancini D, Lopes $E$, Singh $S$. Heterogeneous point mutations in the BRCA 1 breast cancer susceptibility gene occur in high frequency at the site of homonucleotide tracts, short repeats and methylatable $\mathrm{CpG} / \mathrm{CpNpG}$ motifs. Oncogene 1996;12:2623-9.

23 Rodenhiser DI, Andrews JD, Mancini DN, Jung JH, Singh SM. Homonucleotide tracts, short repeats and $\mathrm{CpG} / \mathrm{CpNpG}$ motifs are frequent sites for heterogeneous mutations in the neurofibromatosis type (NF1) tumor-suppressor gene. Mutat Res 1997;373:185-95

24 Laken SJ, Peterson GM, Gruber SB, Oddoux C, Ostrer H, Giardiello FM, Hamilton SR, Hampel H, Markowitz A, Klimstra D, Jhanwar S Winawer S, Offit K, Luce MC, Kinzler KW, Vogelstein B. Familial colorectal cancer in Ashkenazim due to a hypermutable tract in APC. Nat Genet 1997; 17:79-83.

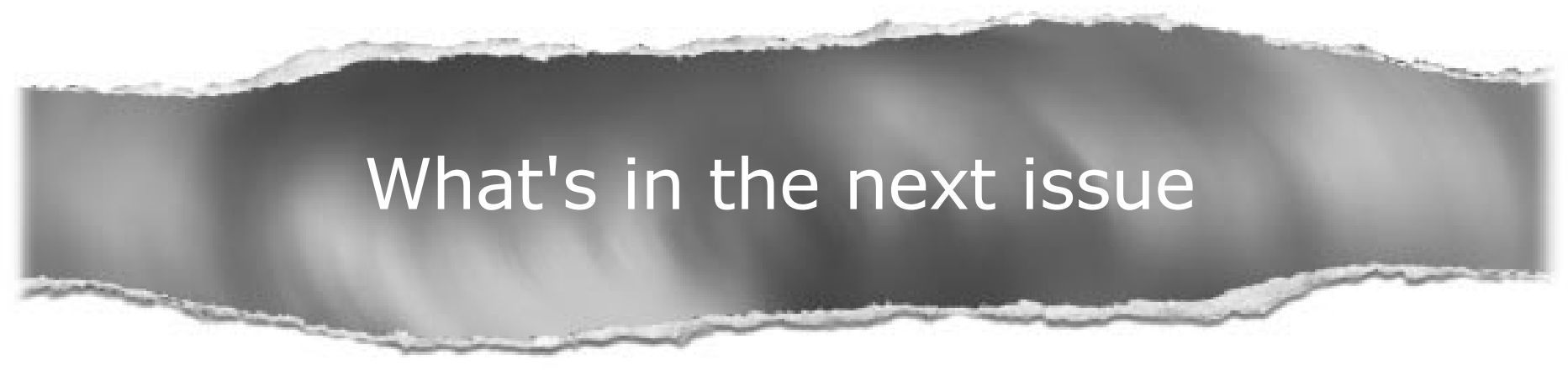

Future content

See which articles have just been accepted for publication and preview the table of contents for the next issue a month before it is published

www.jmedgenet.com 


\section{PostScript}

\section{BOOK REVIEW}

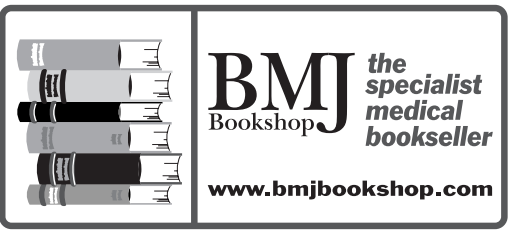

\section{Molecular Cytogenetics Protocols and Applications}

Methods in Molecular Biology Volume 204 Editor Yao-Shan Fan. (Pp 424; \$135.00. Totowa, NJ: Humana Press. 2002. ISBN 1-58829-006-9.

This book is a very up to date manual covering the background, methodologies, and applications of molecular cytogenetics techniques. The emphasis is on the diagnostic applications of FISH in the many areas of medicine on which it impinges, including paediatrics, fetal and reproductive medicine, pathology, haematology, oncology, and, of course, medical genetics. With 27 chapters and over 60 authors, all of whom are experts in their field this book clearly shows how far molecular cytogenetics techniques have developed over the last two decades.

The book is divided into three parts. Part 1 covers the basic concepts and techniques. The opening chapter by the editor Yao-Shan Fan provides a very helpful overview of the scope of the book and an extensive set of references for further reading. The following chapters cover probe labelling (DNA and RNA probes) and basic FISH techniques. The second part of the book is devoted to evolving techniques and applications and includes chapters on microdissection, PRINS, SKY FISH, M FISH, CGH, colour banding FISH, fibre FISH, multitelomere FISH, fluorescence genotyping for telomeric regions, and microarray CGH. Spe cial applications of molecular cytogenetic techniques in chromosomal disorders are cov ered in part 3 of the book. These includ chapters on the application of FISH to the delineation of marker chromosomes and the diagnosis of microdeletion syndromes. Other chapters cover FISH interphase nuclei screening for prenatal diagnosis including preimplantation diagnosis and fetal cells in the maternal circulation, in addition to the interphase FISH screening of routine amniotic fluid samples. This section concludes with a chapter on the application of FISH and CGH in reproductive pathology. The fourth and final section of the book covers the application of molecular cytogenetic techniques to cancer diagnosis. Chapters include the use of CGH in cancer investigations and the application of interphase FISH for the BCR/ABL rearrangements in CML and for HER2 amplification in breast cancer. Also included in this section are the interesting combined approaches, firstly of chromogenic in situ hybridisation with FISH in pathology and secondly simultaneous fluorescence immunophenotyping and FISH on tumour cells.

With any multiauthor book, there are bound to be differences in approach to the writing of individual contributions. This book has taken a surprisingly consistent approach, perhaps an illustration of good editorial control. All of the chapters have good introductory sections and are well referenced, as well as containing the authors' preferred methodologies. Each chapter also includes a comprehensive notes section (effectively tips and troubleshooting advice from the experts). However, a major problem with the book is the lack of comparison between different molecular techniques. In the preface, it is suggested that the book should help the technologist or cytogeneticist determine which procedure to perform for an informative result. I am not sure that the book provides this, as most if not all of the contributors are bound to select their own preferred methodology. For example, in the chapter on FISH screening for telomere abnormalities, an otherwise excellent chapter by Samantha Knight and Jonathan Flint, the practical application of only one of the two commercially available probe sets for this test is covered. More importantly, elsewhere in the book there is a first class chapter on interphase FISH for prenatal diagnosis of common aneuploidies by Baruch Feldman et al. This covers the topic extremely comprehensively and provides 89 literature citations. However, there is no mention, as far as I could see, throughout the book of the other alternative molecular approach of quantitative fluores cence PCR for prenatal aneuploidy detection. While it may be reasonable to excuse the editor by saying that the book is not designed to cover purely molecular genetic techniques, in the same section as the prenatal FISH, there is a chapter on the molecular detection of uniparental disomy. This chapter sits rather incongruously among the others, but is in itself a useful and important topic. Another chapter which seems to have lost its place describes the BAC resource for molecular cytogenetics. This is the final chapter in the book, which appears to have been added as an afterthought. Surely this should have been in evolving techniques and applications rather than "special applications in oncology". The oncology applications would also have benefited from more chapters, for example, haematological disorders other than CML, solid tumour FISH (other than HER2), and perhaps a chapter on the screening of urine samples for bladder cancer.

Perhaps these topics are covered in the companion volume (Methods in molecular biology, volume 220. Cancer cytogenetics: methods and protocols). Another criticism is that the provision of colour plates is very variable. Some chapters are well illustrated, others less so. For example, the chapter on SKY FISH relies on black and white illustrations, whereas the MFISH chapter has glorious full colour images. Furthermore, the overall size of the book is relatively small $(16 \mathrm{~cm}$ by $24 \mathrm{~cm}$ ) and the size of typesetting and tight layout does not make for easy reading when compared with, for example, Rooney's "Human cytogenetics: a practical approach".

On the plus side, there is an incredibly large amount of information packed into this volume, none of it superfluous. Although other textbooks that cover FISH techniques are available, this book provides a more comprehensive, up to date, and thorough coverage of diagnostic molecular cytogenetics than any of the other books currently available.

In summary, I would recommend it as a reference source for everyone working in and interested in the exciting field of diagnostic and research molecular cytogenetics.

Lionel Willatt 


\section{NOTICE}

\section{European Human Genetics \\ Conference 3 - 6 May 2003 ICC, Birmingham, England}

Plenary sessions

- Low Penetrance Genes and Cancer Susceptibility

- Public Issues - Population DNA Banks

- Recent Developments in Neurogenetics

\section{Symposia}

- Bioinformatics

- Stem cells

- Sensory genetics

- Alternative splicing

- Cancer genetics

- Alzheimer disease

- SNPs and haplotypes

- Chromosomes in genetic disease

- Genetics and endocrine problems

\section{Workshops}

- Syndrome identification

- Cytogenetics

- Problems in counselling/ethics

- Genotyping and mutation detection arrays - practical problems

- Quality control

- Prenatal cytogenetics

- Community genetics

\section{Abstract deadline}

Will be via world wide web. Closing date 13 January 2003.

Further information available from: The Vienna Medical Academy of Postgraduate Medical Education and Research, Alserstrasse 4, A-1090 Vienna, Austria. Tel +431 4051383 22 Email:eshg@medacad.org

\section{CORRECTIONS}

In the October 2002 issue of the journal, in the paper by Van Maldergem et al ( $\mathrm{J}$ Med Genet 2002;39:722-33), we regret that some of the authors' names and affiliations were inadvertently omitted. They were:

N Tubiana-Rufi

Service d'Endocrinologie Pédiatrique, Hôpital Robert-Debré, Paris, France

A Mégarbané

Unité de Génétique Médicale, Université Saint-Joseph, Beirut, Lebanon

J Maassen

Silvius Laboratory, University of Leiden Medical Centre, Leiden, The Netherlands

M Polak

INSERM U457, Université Paris VIII, Paris, France
D Lacombe

Service de Génétique Médicale, Hôpital Pellegrin-Enfants, Bordeaux, France

C R Kahn

Joslin Diabetes Center, Harvard University, Boston, USA

E L Silveira

Private Practice, Porto Alegre, Brazil

F H D'Abronzo

Department of Endocrinology, Faculdade de Medicina de Jundiaí, Brazil

F Grigorescu

Molecular Endocrinology, IURC, Montpellier, rance

S O'Rahilly

Department of Medicine and Clinical Biochemistry, Addenbrooke's Hospital, Cambridge, UK

In the July 2002 issue of the journal, in the Online mutation report by Olivieri et al (p e39), there was a missprint in table 2. For No 12 the mutation should have been $031 \mathrm{G}>\mathrm{T}$ instead of $1006 \mathrm{G}>\mathrm{T}$.

In the December 2002 issue of the journal, in the paper by Khoo et al (pp 906-912), all c.1732delTCinsAC mutations should read C.1732delTCinsA. This error occurs on page 906 (Abstract) and page 910 (Discussion). 